\title{
Intestinal absorption of sorbitol and effects of its acute administration on glucose homeostasis in normal rats
}

\author{
BY A.-M. LAUWERS, C. DAUMERIE AND J. C. HENQUIN* \\ Unité de Diabétologie et Nutrition, Université de Louvain, Faculté de Médecine, \\ $U C L$ 54.74, B-1200 Brussels, Belgium
}

(Received 25 September 1984 - Accepted 11 February 1985)

\begin{abstract}
1. Intestinal absorption of sorbitol was studied in a duodeno-jejunal loop of anaesthetized rats. The acute effects of exogenous sorbitol on glucose homeostasis were also evaluated in male and female rats.

2. In the presence of lumen concentrations of sorbitol ranging from $1 \mu \mathrm{M}$ to $200 \mathrm{mM}$, a fairly constant low percentage (about $12 \%$ ) of the loop's contents was absorbed after $30 \mathrm{~min}$. This amount increased only slightly with time, but this was not due to sorbitol accumulation in the mucosal layer of the loop.

3. 3-O-methylglucose was absorbed much more quickly than sorbitol, but did not interfere with sorbitol absorption. The latter was not impaired by omission of lumen sodium ions nor by phloridzin, both of which inhibited 3-O-methylglucose absorption.

4. Gastric administration of sorbitol did not affect plasma glucose or insulin levels. Glucose or sucrose administration caused a similar rise in plasma glucose, but the increase in plasma insulin levels was larger after glucose than after sucrose administration.

5. Intravenous administration of sorbitol slightly increased plasma glucose and insulin levels. These changes were, however, considerably smaller than those occurring after glucose administration.

6. In the normal rat, intestinal absorption of sorbitol is passive and proceeds at a low rate. Acute oral administration of sorbitol does not affect glucose homeostasis, which is only slightly disturbed by a large intravenous load of sorbitol.
\end{abstract}

Sorbitol was first proposed as an alternative sweetener more than 50 years ago (Thannhäuser \& Meyer, 1929). Two advantages over glucose and sucrose have been emphasized repeatedly to justify its wide use: (1) slow and only partial intestinal absorption, (2) rapid metabolism, largely independent of insulin (Förster, 1974; Mehnert et al. 1975; Brunzell, 1978).

The opinion that sorbitol is only slowly absorbed rests on the studies carried out in rats and in man (Mehnert \& Förster, 1961; Mehnert et al. 1975). However, these studies contradicted earlier measurements (Wick et al. 1951) and were not confirmed by very recent ones (Ertel et al. 1983), which suggested that a substantial proportion of sorbitol can be absorbed within $1 \mathrm{~h}$ of ingestion. Furthermore, all these experiments were performed with one single, high amount of intestinal sorbitol.

In the present study, we therefore have re-evaluated the intestinal absorption of sorbitol in anaesthetized rats. The measurements were carried out in the presence of a wide range of lumen concentrations of sorbitol, at different sites of the intestine and under conditions permitting an insight into the mechanism of its absorption. To study the effects of exogenous sorbitol on glucose homeostasis, plasma glucose and insulin levels were measured after acute oral and intravenous administration of sorbitol. They were compared with the changes brought about by glucose or sucrose administration.

* Address all correspondence and reprint requests to Dr J. C. Henquin, Unité de Diabétologie et Nutrition, UCL 54.74, Ávenue Hippocrate 54, B-1200, Brussels (Belgium). 


\section{MATERIALS AND METHODS}

Intestinal absorption

The experiments were performed with male Wistar rats $(250-300 \mathrm{~g})$ fasted for $24 \mathrm{~h}$. They were anaesthetized by an intraperitoneal injection of thiopental $(55 \mathrm{mg} / \mathrm{kg}$ body-weight) followed, when required, by an additional intramuscular injection $(10 \mathrm{mg} / \mathrm{kg}$ body-weight). Body temperature was maintained at $37^{\circ}$ with a heating pad.

Absorption was measured in a tied duodeno-jejunal loop (Salem et al. 1965), but a few experiments were also made with the terminal segment of the ileum. The technique has been described in detail elsewhere (Daumerie \& Henquin, 1982a,b). It permits calculation of the absorption from the difference between the amount of a radioactive substance introduced in the loop and the amount recovered by washing, after correction for the amount of substance remaining in the intestinal wall. In brief, $2 \mathrm{ml}$ of a salt-balanced medium (130 mM-sodium chloride, $6 \mathrm{~mm}$-potassium chloride, $1 \mathrm{~mm}$-calcium chloride, $1 \mathrm{~mm}$ magnesium chloride, $10 \mathrm{~mm}$-sodium bicarbonate; gassed with oxygen-carbon dioxide $(94: 6 \mathrm{v} / \mathrm{v}), \mathrm{pH} 6.9)$ were introduced into the loop. The medium was supplemented with various concentrations of sorbitol (Serva, Heidelberg, Germany) or 3-O-methylglucose (Sigma, St Louis, MO, USA), and a trace amount of the test substance uniformly labelled with ${ }^{14} \mathrm{C}$ (Amersham International, Amersham, Bucks). The amount of radioactive sorbitol was taken into account when the concentration of sorbitol tested was low $(1-10 \mu \mathrm{M})$. When the concentration of sorbitol was high $(200 \mathrm{~mm})$, that of $\mathrm{NaCl}$ was lowered to $30 \mathrm{~mm}$. Nominally Na-free solutions were prepared by substituting choline salts for $\mathrm{Na}$ salts. At the end of the experiment, the intestinal loop was digested as described by Michaels et al. (1979), before determination of its radioactive content.

\section{Glucose homeostasis}

The experiments were performed with male (250-300 g) and female (180-220 g) Wistar rats fasted for $18 \mathrm{~h}$. Before the tests, the animals received an intraperitoneal injection of a low dose of thiopental $(15 \mathrm{mg} / \mathrm{kg}$ body-weight), repeated after $1 \mathrm{~h}$ during the oral tests. Such a low dose only induced drowsiness, but made it possible to sample blood (by cutting the tip of the tail) on quiet animals.

Two groups of thirteen males and females underwent four oral tests, and two groups of thirteen animals underwent four intravenous tests, at 2-week intervals. They received, in random order, glucose, sorbitol or sucrose dissolved in water or, as control, a saline solution $(150 \mathrm{~mm}-\mathrm{NaCl})$. For the oral tests, the substance studied was introduced directly into the stomach, through a fine catheter, at a dose of $2 \mathrm{~g} / \mathrm{kg}$ body-weight, and in a volume of $2 \mathrm{ml}$. For the intravenous tests, the substance studied was injected into a tail vein, at a dose of $1 \mathrm{~g} / \mathrm{kg}$ body-weight, and in a volume of $0.5 \mathrm{ml}$. Plasma glucose was measured by a glucose oxidase (EC 1.1.3.4) method (Glucose Analyzer; Beckman), and plasma insulin was measured by a double-antibody radioimmunoassay, using rat insulin as standard (Novo Research Institute, Bagsvaerd, Denmark).

\section{Presentation of results}

All results are presented as means with their standard errors for the indicated number of rats. Statistical comparisons were made with Student's $t$ test for unpaired or paired values, as appropriate.

\section{RESULTS}

\section{Intestinal absorption of sorbitol}

Sorbitol absorption by the duodeno-jejunal loop was studied in the presence of lumen concentrations of sorbitol ranging from $1 \mu \mathrm{M}$ to $200 \mathrm{mM}$. Fig. 1 shows that a fairly constant 
percentage $(11 \cdot 6-13.7 \%)$ of the initial sorbitol content of the loop was absorbed after 30 min. This, obviously, corresponded to very different absolute amounts: 0.82 (SE 0.05) $\mathrm{nmol} / \mathrm{g}$ dry intestine in the presence of $1 \mu \mathrm{M}$ lumen sorbitol, and 139 (SE 11) $\mu \mathrm{mol} / \mathrm{g}$ dry intestine in the presence of $200 \mathrm{~mm}$-sorbitol. The fraction of sorbitol absorbed increased with time, but not to the same extent at all concentrations of sorbitol (Fig. 1). Between 30 and $120 \mathrm{~min}$, the increase was about $2 \cdot 3$-fold and $1 \cdot 3$-fold in the presence of low $(1-10 \mu \mathrm{M})$ or high $(20-200 \mathrm{mM})$ concentrations of sorbitol respectively.

Since the accumulation of sorbitol in the intestinal mucosa could hamper the absorption from the lumen, the concentrations of sorbitol in the mucosal and muscle layers of the loop were determined at the end of the $120 \mathrm{~min}$ absorption periods (Table 1). In the mucosa it did not exceed $10 \%$ of the initial lumen concentration of sorbitol, but was approximately two-fold higher than in the muscle layer.

At the level of a terminal loop of the ileum, sorbitol absorption amounted to 10.5 (SE 1.2$) ~ \mu \mathrm{mol} / \mathrm{g}$ dry intestine after $30 \mathrm{~min}$, when the initial lumen concentration was $20 \mathrm{mM}$ $(n 7)$. This value was lower $(P<0.01)$ than that measured in a duodeno-jejunal loop (15.8 (SE $1 \cdot 2) \mu \mathrm{mol} / \mathrm{g}$ dry intestine).

In further experiments, the absorption of sorbitol was compared with that of 3$O$-methylglucose in duodeno-jejunal loops. At similar lumen concentrations, approximately six times more 3-O-methylglucose than sorbitol was absorbed (Table 2). This amount corresponded to 88.7 (SE 0.9 ) and 75.9 (SE 3.2) \% of the loop's contents after $30 \mathrm{~min}$, in the presence of 2 and $20 \mathrm{~mm}-3-O$-methylglucose respectively. Table 2 also shows that 3$O$-methylglucose did not interfere with sorbitol absorption. 3-O-methylglucose absorption was decreased by $25 \%$ in the presence of a ten-fold higher concentration of sorbitol, at least when the concentration of 3-O-methylglucose was $20 \mathrm{~mm}$. Sorbitol was ineffective in the presence of 2 mм-3-O-methylglucose.

Phloridzin did not affect sorbitol absorption, which slightly increased in the absence of lumen sodium ions. By contrast, 3-O-methylglucose absorption was decreased by $\mathrm{Na}^{+}$ omission and strongly inhibited by phloridzin (Fig. 2).

\section{Glucose homeostasis}

Before oral or intravenous administration of the test substances $(0 \mathrm{~min})$, the average plasma glucose concentration was 4.96 (SE 0.04) $\mathrm{mM}$ and 4.88 (SE 0.07) $\mathrm{mM}$ in male and female rats respectively. The average plasma insulin concentration was 0.49 (SE 0.02$) \mathrm{ng} / \mathrm{ml}$ and 0.54 (SE 0.03$) \mathrm{ng} / \mathrm{ml}$ respectively.

Introduction of glucose into the stomach of the animals was followed by a rapid rise in plasma glucose levels (Fig.3). The peak value was not different in males and females, but the return to control values was faster in females. Concomitantly there occurred an increase in plasma insulin levels, which was also more transient in females than in males (Fig. 4). Plasma glucose levels also increased after gastric administration of sucrose. The initial rise was not significantly lower than after glucose, but elevated levels persisted until $180 \mathrm{~min}$ (Fig. 3). Plasma insulin levels increased less than with the glucose load $(P<0.02$ at $30 \mathrm{~min})$, but reached a plateau which lasted until the end of the test. Sorbitol was without significant effect on plasma glucose (Fig. 3) and plasma insulin (Fig. 4) levels in males or females. Administration of $\mathrm{NaCl}$ caused a progressive fall in plasma glucose levels, which was more pronounced in females than in males (Fig. 3), and was not accompanied by significant changes in plasma insulin levels (Fig. 4).

Intravenous injection of glucose induced an important, but short-lasting rise in plasma glucose (Fig. 5) and plasma insulin (Fig. 6) levels. The recovery of normal plasma glucose levels was faster in females than in males, as attested by a higher glucose disappearance rate (Conard, 1955): 6.37 (SE 0.29) v. 5.04 (SE 0.39) \% / $\min (P<0.02)$. The rise in plasma 


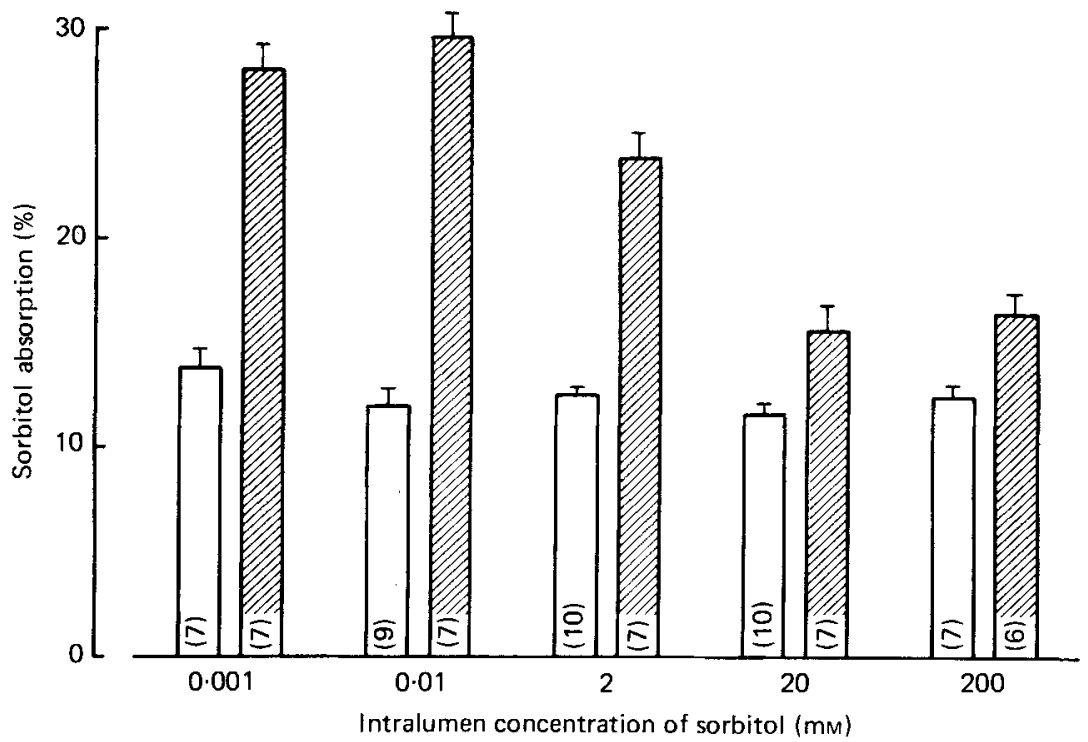

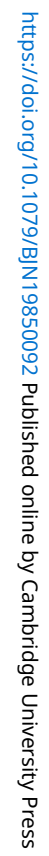

Fig. 1. Effect of time on sorbitol absorption by a duodeno-jejunal loop in anaesthetized male rats. The initial concentration of sorbitol in the solution introduced in the loop was as indicated. Absorption after $30 \mathrm{~min}(\square)$ or $120 \mathrm{~min}$ (圈) is expressed as \% of the initial sorbitol content of the loop. Values are means with their standard errors represented by vertical bars. Numbers of rats are indicated in parentheses.
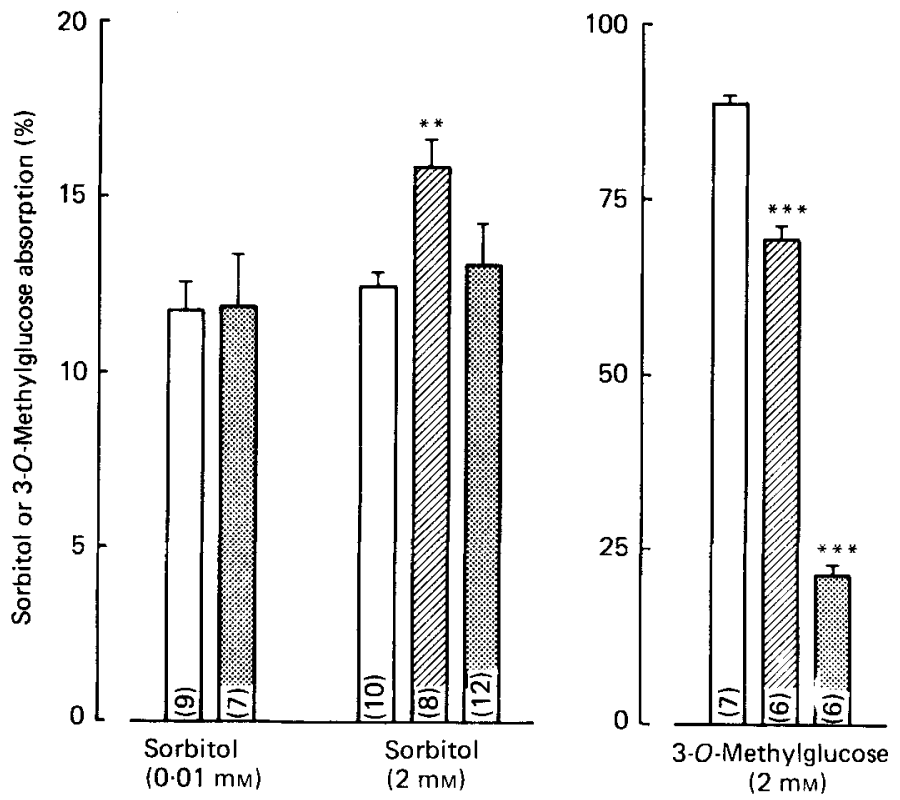

Fig. 2. Effects of sodium ion omission (勿) and of $0.1 \mathrm{~mm}$-phloridzin (图) on sorbitol or 3-O-methylglucose absorption by a duodeno-jejunal loop in anaesthetized male rats. Controls $(\square)$. The initial concentration of the test substance in the solution introduced in the loop was as indicated. Absorption after $30 \mathrm{~min}$ is expressed as \% of the initial sorbitol or 3-O-methylglucose content of the loop. Values are means with their standard errors represented by vertical bars. Numbers of rats are indicated in parentheses. Mean values were significantly different from controls (unpaired $t$ test): ${ }^{* *} P<0.01,{ }^{* * *} P<0.001$. 
Table 1. Estimated concentration of sorbitol in the wall of the duodeno-jejunal loop at the end of a 120 min period of absorption

(Mean values with their standard errors for seven rats. After careful washing at the end of the absorption period, the intestinal loop was opened and the mucosal and muscle layers were separated by scraping. Their respective water contents were determined by the difference between wet and dry weights. Their radioactive contents were then measured to estimate the concentration of sorbitol (/I water) in each layer. This calculation was based on the specific radioactivity of $\left[{ }^{14} \mathrm{C}\right]$ sorbitol introduced in the loop. The results are expressed as \% of the initial intralumen concentration of sorbitol)

\begin{tabular}{|c|c|c|c|c|}
\hline \multirow{3}{*}{$\begin{array}{l}\text { Intralumen concentration } \\
\text { of sorbitol (mM) }\end{array}$} & \multicolumn{4}{|c|}{$\begin{array}{l}\text { Sorbitol concentration in the intestinal wall } \\
(\% \text { of the initial intralumen concentration) }\end{array}$} \\
\hline & \multicolumn{2}{|c|}{ Mucosal layer } & \multicolumn{2}{|c|}{ Muscle layer } \\
\hline & Mean & $\mathrm{SE}$ & Mean & SE \\
\hline 0.001 & $9 \cdot 6$ & 1.3 & 5.9 & $0.1^{* *}$ \\
\hline 0.01 & 7.4 & 0.9 & $4 \cdot 1$ & $0.3^{* *}$ \\
\hline & 10.8 & $2 \cdot 4$ & $4 \cdot 2$ & $0.3^{*}$ \\
\hline 20 & 7.6 & 1.5 & $4 \cdot 0$ & $0.7^{*}$ \\
\hline
\end{tabular}

Mean values for sorbitol concentration in mucosal and muscle layers were significantly different (paired $t$ test):

* $P<0.05$, ** $P<0.01$.

Table 2. Sorbitol or 3-O-methylglucose absorption by a duodeno-jejunal loop in anaesthetized rats

(Mean values with their standard errors; no. of rats in parentheses. To measure absorption of sorbitol or 3-O-methylglucose, the test substance was introduced into the loop at the indicated concentration. The solution $(2 \mathrm{ml})$ was supplemented with a trace amount of either [U-14 $\mathrm{C}]$ sorbitol or $3-O$-methy]$\mathrm{D}-\left[\mathrm{U}-{ }^{14} \mathrm{C}\right] \mathrm{glucose}$. The reciprocal influences of each substance on the absorption of the other were tested separately; only one tracer was used in each experiment)

\begin{tabular}{|c|c|c|c|c|c|}
\hline \multirow{2}{*}{\multicolumn{2}{|c|}{ Intralumen concentration (mM) }} & \multicolumn{4}{|c|}{ Amount of substance absorbed $(\mu \mathrm{mol} / \mathrm{g}$ dry intestine per $30 \mathrm{~min})$} \\
\hline & & \multicolumn{2}{|c|}{ Sorbitol } & \multicolumn{2}{|c|}{ 3-O-Methylglucose } \\
\hline Sorbitol & 3-O-Methylglucose & Mean & $\mathrm{SE}$ & Mean & $\mathrm{SE}$ \\
\hline 2 & - & 1.52 & $0.06(10)$ & - & - \\
\hline 20 & - & $15 \cdot 8$ & $1.2(10)$ & - & $\ldots$ \\
\hline 200 & - & 139 & $11(7)$ & - & - \\
\hline- & 2 & - & - & $9 \cdot 67$ & $0.34(7)$ \\
\hline$\ldots$ & 20 & - & - & 89.6 & $6.2(7)$ \\
\hline 20 & 2 & 13.8 & $0.9(7)$ & $9 \cdot 17$ & $0.57(7)$ \\
\hline 20 & 20 & 14.9 & $0.9(6)$ & 92.0 & $4 \cdot 2(6)$ \\
\hline 200 & 20 & 166 & $18(7)$ & $67.7^{*}$ & $5 \cdot 2(7)$ \\
\hline
\end{tabular}

* Mean value was significantly different from amount of 3-O-methylglucose absorbed in the absence of sorbitol (unpaired $t$ test): $(P<0.02)$. 


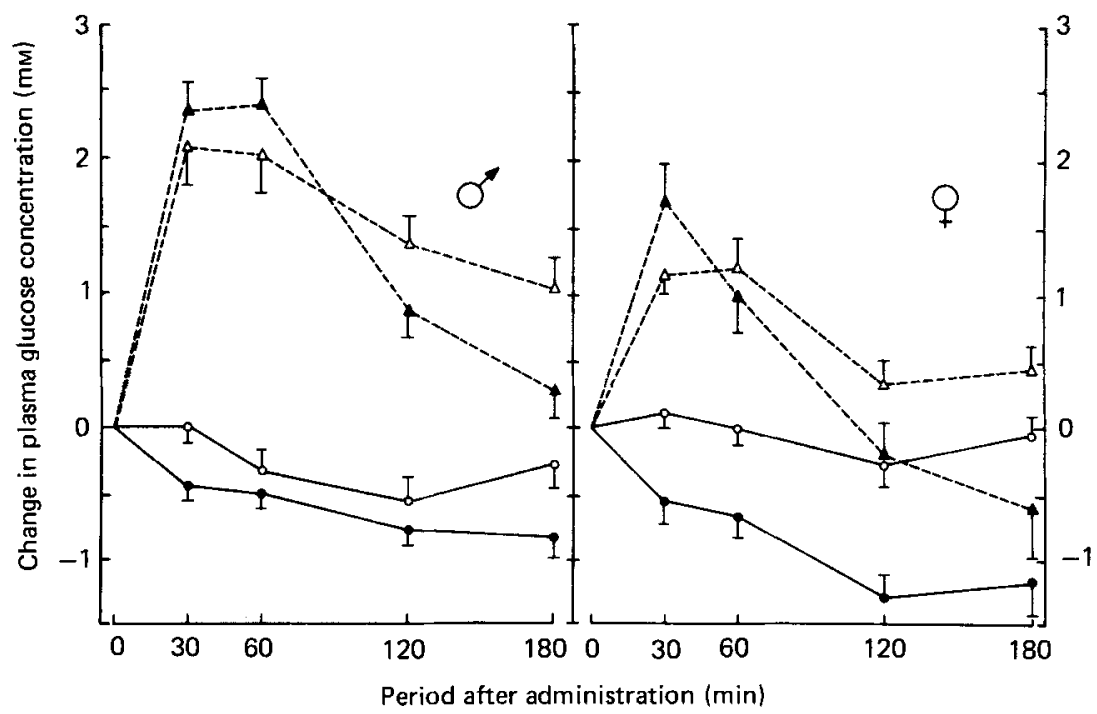

Fig. 3 Changes in plasma glucose concentration in male or female rats after oral administration of sodium cnloride $(\boldsymbol{O})$, glucose $(\boldsymbol{A})$, sorbitol $(O)$ or sucrose $(\Delta)$. The amount of test substance administered was $2 \mathrm{~g} / \mathrm{kg}$ body-weight (in $2 \mathrm{ml}$ water) or $2 \mathrm{ml} 150 \mathrm{~mm}-\mathrm{NaCl}$. Each animal received the four different oral loads at intervals of 2 weeks and in random order. Values are means with their standard errors represented by vertical bars for thirteen male and thirteen female rats.

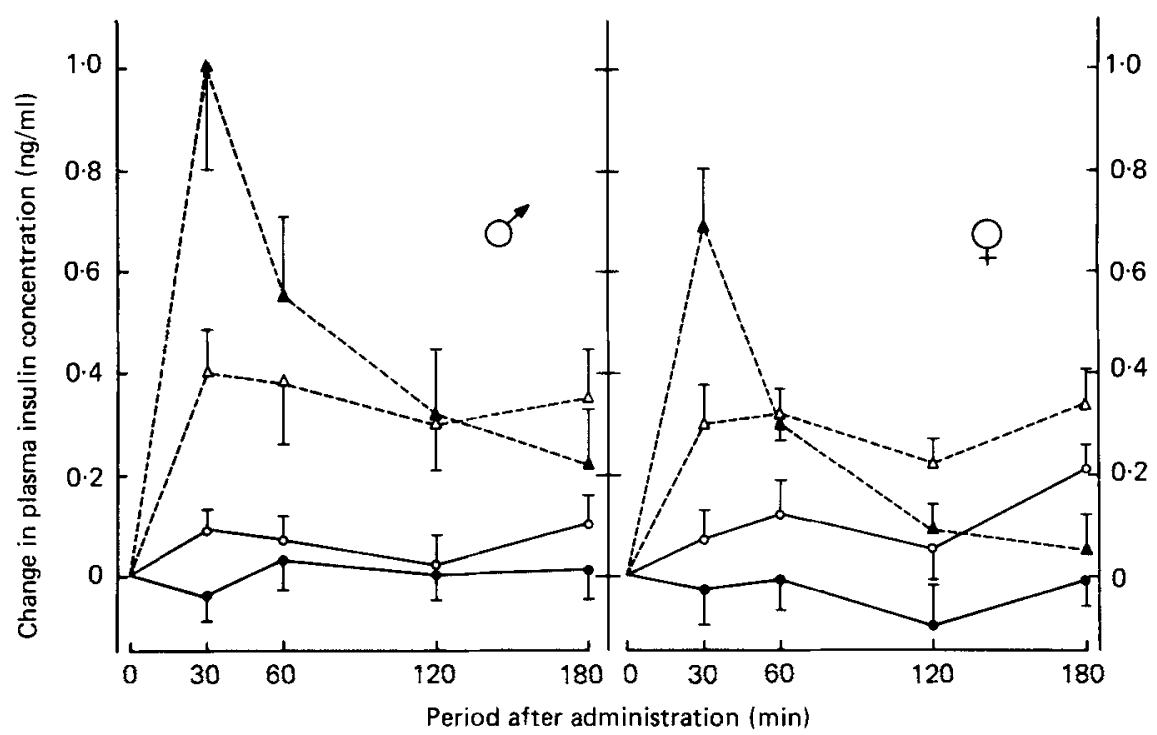

Fig. 4. Changes in plasma insulin concentration in male or female rats after oral administration of sodium chloride $(\mathbf{O})$, glucose $(\Delta)$, sorbitol $(O)$ or sucrose $(\triangle)$. The amount of test substance administered was $2 \mathrm{~g} / \mathrm{kg}$ body-weight (in $2 \mathrm{ml}$ water) or $2 \mathrm{ml} 150 \mathrm{~mm}-\mathrm{NaCl}$. Each animal received the four different oral loads at intervals of 2 weeks and in random order. Values are means with their standard errors represented by vertical bars for thirteen male and thirteen female rats. 


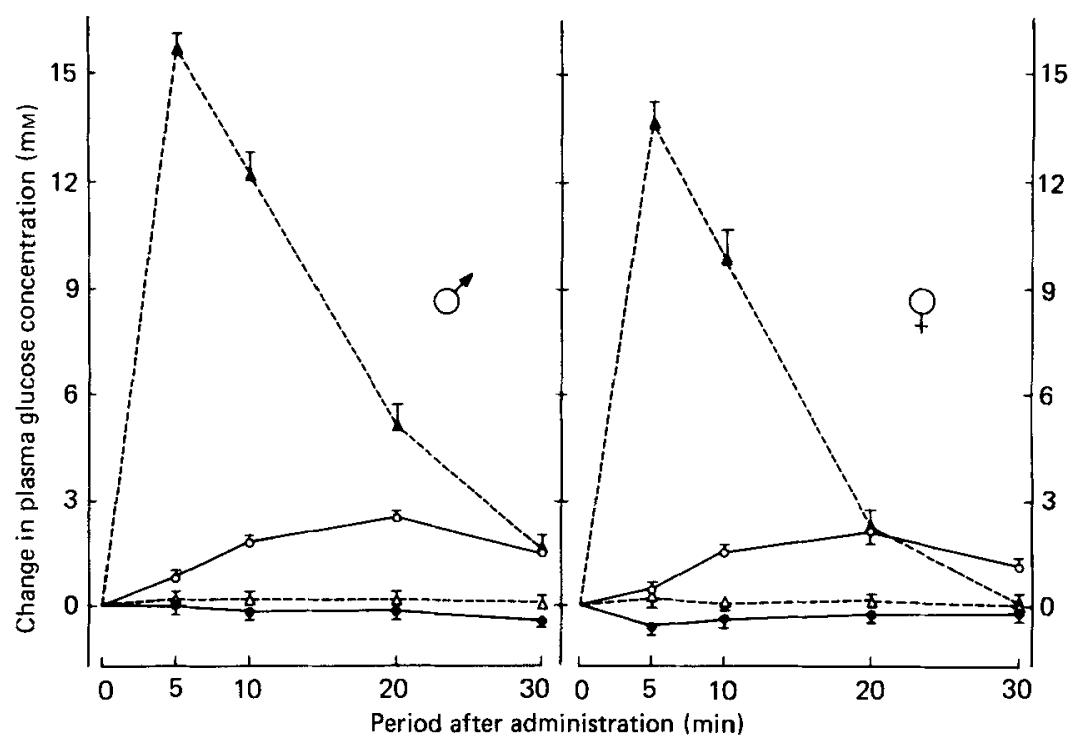

Fig. 5. Changes in plasma glucose concentration in male or female rats after intravenous administration of sodium chloride $(\Theta)$, glucose $(\Delta)$, sorbitol $(O)$ or sucrose $(\triangle)$. The amount of test substance administered was $1 \mathrm{~g} / \mathrm{kg}$ body-weight (in $0.5 \mathrm{ml}$ water) or $0.5 \mathrm{ml} 150 \mathrm{~mm}-\mathrm{NaCl}$. Each animal received the four different intravenous loads at intervals of 2 weeks and in random order. Values are means with their standard errors represented by vertical bars for thirteen male and thirteen female rats.

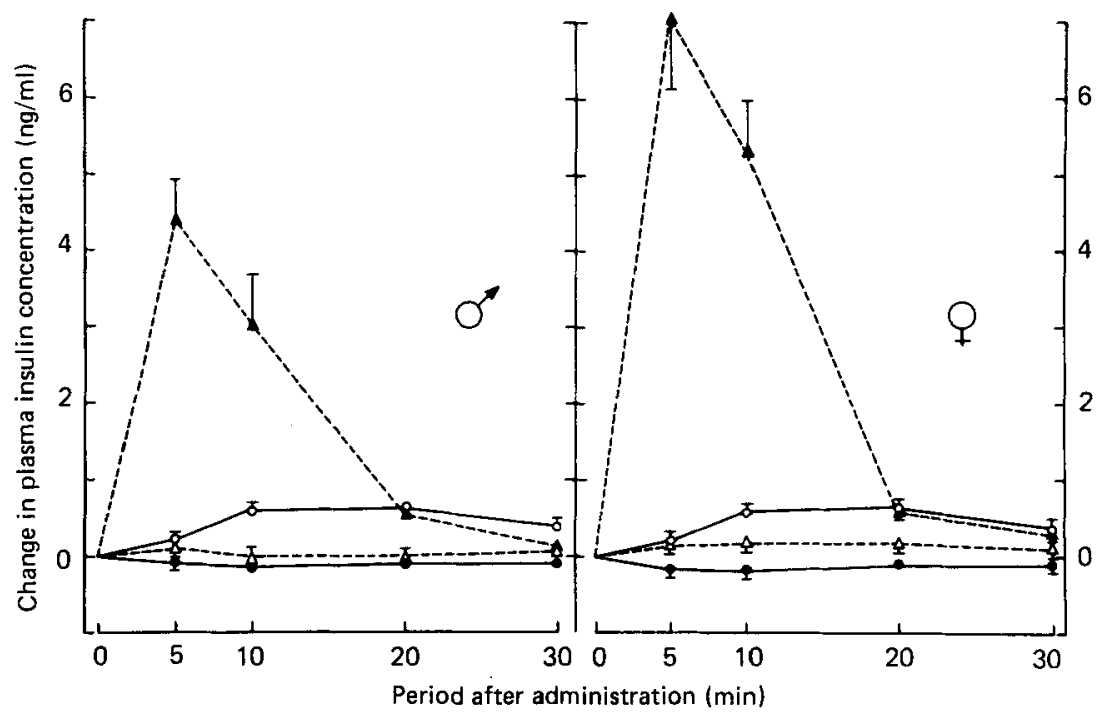

Fig. 6. Changes in plasma insulin concentration in male or female rats after intravenous administration of sodium chloride $(\boldsymbol{O})$, glucose $(\mathbf{\Delta})$, sorbitol $(O)$ or sucrose $(\Delta)$. The amount of test substance administered was $1 \mathrm{~g} / \mathrm{kg}$ body-weight (in $0.5 \mathrm{ml}$ water) or $0.5 \mathrm{ml} 150 \mathrm{~mm}-\mathrm{NaCl}$. Each animal received the four different intravenous loads at intervals of 2 weeks and in random order. Values are means with their standard errors represented by vertical bars for thirteen male and thirteen female rats. 
insulin levels was also significantly greater in females $(P<0.02)$. Neither plasma glucose nor plasma insulin levels were modified by the intravenous injection of sucrose. On the other hand, intravenous sorbitol caused a small, progressive increase in plasma glucose (Fig. 5) and plasma insulin (Fig. 6) levels. Intravenous administration of $\mathrm{NaCl}$ was without effect in males and only produced a modest decrease in plasma glucose and insulin levels at $5 \mathrm{~min}$ in females.

\section{DISCUSSION}

The present results show that, in the rat, the intestinal absorption of sorbitol is about six times slower than that of 3-O-methylglucose, a non-metabolized sugar, known to be absorbed like glucose (Crane, 1960). The results support the conclusions of Mehnert and co-workers (Mehnert \& Förster, 1961; Mehnert et al. 1975) and extend these earlier studies in showing that sorbitol absorption proceeds at a low rate, whatever its lumen concentration (between $1 \mu \mathrm{M}$ and $200 \mathrm{mM}$ ). The evidence obtained suggests that the absorption is purely passive, and occurs by pathways which are different from those responsible for the absorption of 3-O-methylglucose. First, the absolute amount of sorbitol absorbed was directly proportional to the initial lumen concentration (the percentage absorbed was fairly constant). Second, sorbitol absorption was not impaired by $\mathrm{Na}^{+}$omission or by phloridzin, two conditions that inhibited the active transport of 3-O-methylglucose. Third, 3-Omethylglucose was without effect on sorbitol absorption. Fourth, sorbitol failed to alter active transport of 3-O-methylglucose and partially reduced its passive transport only when it was used at a ten times higher concentration. Our conclusion of a passive absorption of sorbitol in vivo is in keeping with results obtained in vitro (Wilson \& Crane, 1958). It is, however, somewhat surprising that the relative absorption of sorbitol did not fall when the lumen concentration was only 1 or $10 \mu \mathrm{M}$, since the plasma sorbitol concentration in the rat has been reported to be about $30 \mu \mathrm{M}$ (Sener et al. 1979), i.e. fifteen times higher than in man (Morrison et al. 1970).

Sorbitol absorption increased with time, but the increase was very small at high lumen concentrations. The reasons for this are not clear; it was not due to a loss of viability of the preparation within that period of time (Daumerie \& Henquin, 1982a). A similar observation was also made with rats whose intestines were not tied as in the present technique (Mehnert \& Förster, 1961). Given the low percentage of sorbitol absorbed, the marked decrease in the absorption rate cannot be explained by a commensurate fall in the lumen concentration of sorbitol. One can also exclude that it results from a large increase in plasma sorbitol. Thus, the rise in plasma sorbitol concentration, brought about by sorbitol absorption, was not more than $3 \mu \mathrm{M}$ after oral administration of $100 \mathrm{mg}$ sorbitol to rats (Ertel et al. 1983). This dose is $40 \%$ larger than that given in our experiments with $200 \mathrm{~mm}$-sorbitol in the loop. On the other hand, it was possible that sorbitol accumulated in the mucosa, where its metabolism is minimal because of the extremely low levels of sorbitol dehydrogenase (EC1 . 1 . 1 . 14) (Heinz \& Lambrecht, 1967). Though higher than in the muscle layer of the loop, the concentration of sorbitol in the mucosa was estimated not to exceed $10 \%$ of the initial lumen concentration of sorbitol. This small accumulation may thus contribute to, but is unlikely to be the only factor responsible for, the decrease in the absorption rate with time.

Our findings also demonstrate that sorbitol absorption is not restricted to the duodenojejunum but also takes place, although at a slower rate $(66 \%)$, in the terminal ileum. In this context, it should also be recalled that a substantial proportion of sorbitol that is not absorbed in the small intestine may undergo fermentation in the caecum and the colon (Schnell-Dompert \& Siebert, 1980; Hyams, 1983) and that the resulting products are absorbed. 
Studies using $\left[{ }^{14} \mathrm{C}\right]$ sorbitol have shown that $1-3 \mathrm{~h}$ after gastric administration of $0.4 \mathrm{~g}$ sorbitol $/ \mathrm{kg}$ to rats, approximately $0.1 \mathrm{~mm}$-glucose in the plasma was labelled and thus derived from absorbed sorbitol (Ertel et al. 1983). In the present study, administration of a higher dose of sorbitol $(2 \mathrm{~g} / \mathrm{kg})$ did not alter plasma glucose or plasma insulin levels. In normal man, ingestion of sorbitol $(0.5-0.75 \mathrm{~g} / \mathrm{kg})$ was also without effect on plasma glucose (Förster, 1972; Macdonald et al. 1978) but caused a slight increase in plasma insulin levels in the only study where this factor was measured (Macdonald et al. 1978). Taken together, these results show that, in the rat and in man, glucose homeostasis is perfectly maintained after large gastric loads of sorbitol. The slow absorption of the substance certainly facilitates this control. By contrast, gastric administration of glucose and sucrose increased plasma glucose and insulin levels. Somewhat surprisingly, the rise in plasma insulin was less marked after sucrose than after glucose administration, despite similar increases in plasma glucose. Similar observations were also made in man (Macdonald et al. 1978; Crapo et al. 1980) but have not been satisfactorily explained.

The intravenous injection of sorbitol was followed by a small and progressive increase in plasma glucose accompanied by a parallel increase in plasma insulin. Similar changes were also observed after injection of $1 \mathrm{~g}$ sorbitol/ $\mathrm{kg}$ in the dog (Kuzuya et al. 1969). On the other hand, slow intravenous infusions of lower doses of sorbitol produced no, or very little, change in plasma glucose in rats (Förster, 1974) or in man (Mehnert et al. 1975), even when insulin release was partially inhibited (de Kalbermatten et al. 1980). Glucose homeostasis is thus disturbed only by a rapid and large load of sorbitol. Since injected sorbitol is quickly converted to glucose (Froesch et al. 1971), it may even seem surprising that the rise in plasma glucose was not more marked. However, high amounts of sorbitol are excreted in the urine (Keller \& Froesch, 1971; Pösö \& Hillbom, 1977). Furthermore, sorbitol, or glucose derived from it, may be oxidized or stored by the liver and other tissues (Keller \& Froesch, 1971; Froesch et al. 1971, Förster, 1974), in particular because insulin levels are increased. It is very unlikely that sorbitol itself stimulated insulin release, as proposed for the dog (Kuzuya et al. 1969). Thus, even at a high concentration (16.6 mM), sorbitol failed to stimulate secretion of insulin by isolated islets from the rat, although glucose-induced secretion of insulin is potentiated by sorbitol (Malaisse et al. 1974). The rise in plasma insulin levels seems to be due to the rise in plasma glucose levels. The parallel time course of these two changes fully supports this interpretation.

The authors thank Professor A. E. Lambert for facilities and A. M. Pottier and F. Mathot for invaluable assistance. J.C.H. is Chercheur Qualifié of the FNRS, Brussels. The work was supported by a grant-in-aid from Bayer-Belgium S.A.

\section{REFERENCES}

Brunzell, J. D. (1978). Diabetes Care 1, 223-230.

Conard, V. (1955). Mesures de l'Assimilation du Glucose. Bases Théoriques et Applications Cliniques, pp. 1-140.

Brussels: Acta Medica Belgica.

Crane, R. K. (1960). Physiological Reviews 40, 789-825.

Crapo, P. A., Kolterman, O. G. \& Olefsky, J. M. (1980). Diabetes Care 3, 575-581.

Daumerie, C. \& Henquin, J. C. (1982 a). Gut 23, 140-145.

Daumerie, C. \& Henquin, J. C. (1982 b). Diabète et Métabolisme 8, 1-5.

de Kalbermatten, N., Ravussin, E., Maeder, E., Geser, C., Jecquier, E. \& Felber, J. P. (1980). Metabolism 29, $62-67$.

Ertel, N. J., Akgun, S., Kemp, F. W. \& Mittler, J. C. (1983). Journal of Nutrition 113, 566-573.

Förster, H. (1972). Medizin und Ernährung 12, 7-15.

Förster, H. (1974). In Sugars in Nutrition, pp. 259-280 [H. Sipple and K. Macnutt, editors]. New York: Academic Press.

Froesch, E. R., Zapf, J., Keller, U. \& Oelz, O. (1971). European Journal of Clinical Investigation 2, 8-14.

Heinz, F. \& Lambrecht, W. (1967). Zeitschrift für Physiologische Chemie 348, 855-862. 
Hyams, J. S. (1983). Gastroenterology 84, 30-33.

Keller, U. \& Froesch, E. R. (1971). Diabetologia 7, 349-356.

Kuzuya, T., Kanazawa, Y. \& Kosaka, K. (1969). Endocrinology 84, 200-207.

Macdonald, I., Keyser, A. \& Pacy, D. (1978). American Journal of Clinical Nutrition 31, 1305-1311.

Malaisse, W. J., Sener, A. \& Mahy, M. (1974). European Journal of Biochemistry 47, 365-370.

Mehnert, H., Dietze, G. \& Haslbeck, M. (1975). Nutrition and Metabolism 18, 171-190.

Mehnert, H. \& Förster, H. (1961). Klinische Wochenschrift 11, 596-597.

Michaels, E. B., Hahn, E. C. \& Kenyon, A. J. (1979). Analytical Biochemistry 99, 288-296.

Morrison, A. D., Clements, R. S., Travis, S. B., Oski, F. \& Winegrad, A. I. (1970), Biochemical and Biophysical Research Communications 40, 199-205.

Pösö, A. R. \& Hillbom, M. E. (1977). Biochemical Pharmacology 26, 331-335.

Salem, A. A., Cocco, A. E. \& Hendrix, T. R. (1965). American Journal of Physiology 209, 165-168.

Schnell-Dompert, E. \& Siebert, G. (1980). Zeitschrift für Physiologische Chemie 361, 1069-1075.

Sener, A., Hutton, J. C., Schoonheydt, J., Tinant, A., Urbain, M. \& Malaisse, W. J. (1979). Diabète et Métabolisme $5,217-222$.

Thannhäuser, S. J. \& Meyer, K. H. (1929). Münchener Medizinische Wochenschrift 76, 356-360.

Wick, A. N., Almen, M. \& Joseph, L. (1951). Journal of the American Pharmaceutical Association 40, 542-550.

Wilson, T. H. \& Crane, R. K. (1958). Biochimica et Biophysica Acta 29, 30-44. 